\title{
AIR POLLUTION, CITIZEN DATA COLLECTIVES AND COMMUNICATION AGENDA SETTING IN COLOMBIA
}

\author{
JUAN-CARLOS VALENCIA \& OSCAR FONSECA \\ Department of Communication, Universidad Javeriana, Colombia
}

\begin{abstract}
Air pollution levels in the cities of Bogotá and Medellín (Colombia) are now reaching dangerous levels, as measured by the few government monitoring stations available and operative. So far, government actions have focused on enforcing private car and industrial emission limits, prohibiting the circulation of vehicles for a few days during particularly polluted periods and vague promises of switching a percentage of public transport vehicles to alternative power. Official measurements are increasingly being reported in the national and local media, as well as through social media, but citizen distrust of their quality has mounted. Citizen collectives are starting to work designing low-cost mobile sensors, monitoring pollution in some areas and in public transport, sharing their georeferenced data over the internet and trying to raise awareness of the dangers of pollution and the necessity of radical actions to deal with the problem. This paper describes the current actions of some of these citizen collectives and their results in setting the media and public agenda on air pollution problems.

Keywords: social movements, citizen collectives, air pollution, data activism, Colombia, citizen sensing, participatory monitoring, environmental justice.
\end{abstract}

\section{INTRODUCTION}

Air pollution is a mounting problem in cities from London to Mumbai, from Detroit to Bogotá. An estimated 4.5 billion people around the world are currently exposed to particulate matter (PM) levels above the concentration that the World Health Organization (WHO) considers safe [1]. It is one of the most visible and worrying effects of what some authors call the Anthropocene or the Capitalocene [2]. Air pollution intensification in cities around the world demonstrates that a hegemonic, yet not universal civilizatory model, has reached a breaking point and that its technological solutions cannot really solve the problems it has created and continues to create [3]. The overproduction and widespread use of fossil-fuel powered vehicles, the accelerated growth of urban populations, the expansion and nomadic character of largely environmentally-unfriendly industries, the expansion of power generation plants and the ideas that unlimited consumption and constant economic growth are the ultimate goals of public institutions and private corporations have resulted in a deepening, sadly irreversible environmental crisis. Only highly coordinated, big budgeted, radical actions in places like China have somewhat reversed this trend, but even their air pollution levels are still above WHO's recommended values [4].

There is growing concern among Social Science academics and sectors of public opinion around the world that market forces and democratic institutions are not managing to confront this dangerous crisis: regulations, policies, international agreements, declarations of intent are not resulting in effective solutions and environmental indicators worldwide continue to deteriorate. We are already experiencing the limits to growth [5]. Despair at inaction has led to recent protests in Great Britain such as the so-called Extinction Rebellion. Perhaps our only hope is that, as it has happened in the past, citizens will take direct action, promote real although hard solutions, start civilizatory paradigm transitions and adopt more realistic humans-as-part-of nature lifestyles. This paper comes out of the early stages of participatory research conducted in Colombia, South America with citizen collectives that worried about air-quality deterioration in the cities of Bogotá and Medellin, ineffective or insufficient public 
policies, corruption and irresponsible, short-term corporate decisions, have decided to take a hands on, radical approach. They are designing and building low-cost air-quality sensors, installing them around their under-monitored cities, using mobile monitoring equipment and circulating their data through social media platforms, raising awareness about the problem across all sectors of society and confronting public institutions, officials and corporations with sufficiently accurate, urgent information.

\section{AIR POLLUTION IN BOGOTÁ AND MEDELLIN}

Bogotá is a city of $1775 \mathrm{~km}^{2}$ and more than $8,300,000$ inhabitants. Medellín's size is $1,152 \mathrm{~km}^{2}$ with a population of 3,731,000. Both cities have been important light-industry hubs in Colombia for the past half century. Industries are basically food, chemical, plastics, metallurgy and construction materials. They use carbon, heavy oils and natural gas as fuel for machinery and release particulate matter to the atmosphere. Both cities are located high on the Andes in fairly narrow valleys surrounded by tall mountains, a geography that makes heavy particles and gases difficult to disperse. Private cars and motorcycles, trucks, taxis and public transport vehicles have increased substantially in both cities, especially after neoliberal reforms introduced in the early 1990s. Power generation in Colombia relies mostly on hydroelectric power, although there are some carbon thermoelectric plants running. Farmers displaced from the countryside because of violence have dramatically increased the population of Colombian cities in the past four decades. Most live in precarious settlements in the outskirts of cities, many in unstable terrains on hills and mountains, connected to the flat land through unsealed roads.

The authorities estimate that there could be nearly one million motorcycles, 60,000 taxis, nearly 20.000 public transport vehicles, nearly one million private cars and about 25,000 trucks circulation in Bogotá [6]. They mostly use gasoline and diesel as fuel with a small percentage using natural gas. A subway system was built in Medellin in the 1980s but the one planned for Bogotá has been postponed for decades because of the barriers mounted by special interests. Bogotá introduced Transmilenio, an extensive Bus Rapid Transit System, more than twenty years ago but the buses use Diesel [7]. Citizen and experts' requests that the buses use natural gas went unheard. Legislation to control pollutant emissions has been introduced since the 1970s and the first air quality measurements were conducted in the late 1960s. Fixed and mobile sensors were installed and replaced when they served their lifespan. The Red de Monitoreo de Calidad del Aire de Bogotá (RMCAB) was created and in the mid-1990s it was planning to set up 32 monitoring stations throughout the city that would measure PST, $\mathrm{PM}_{10}, \mathrm{O}_{3}, \mathrm{CO}$ and $\mathrm{NO}_{\mathrm{x}}$ [8]. Two decades later just 13 high-quality fixed sensors were installed and running but there are worrying measurement blackouts and areas of Bogotá that are still unmeasured. The national government introduced mandatory private vehicle emission measurements early in the $21^{\text {st }}$ century and has tightened the thresholds continuously. There have been improvements in the quality of fuels available to the public. But trucks, public transport vehicles, industries and construction works continue to pollute the air and their impact seems to increase year after year. Half of the nearly 2,000 industries registered in Bogotá release high impact emissions.

$\mathrm{PM}_{10}$ is the most significant air pollutant in Bogotá [9]. Annual average $\mathrm{PM}_{10}$ levels for Bogotá range from $9.89 \mu \mathrm{g} / \mathrm{m}^{3}$ to $160 \mu \mathrm{g} / \mathrm{m}^{3}$ with peaks in the months of March and April. $\mathrm{PM}_{10}$ mean is $37.5 \mu \mathrm{g} / \mathrm{m}^{3}$, below the Colombian annual standard of $50 \mu \mathrm{g} / \mathrm{m}^{3}$ but twice as high as the WHO guideline of $20 \mu \mathrm{g} / \mathrm{m}^{3}$ [10]. The sources are fugitive dust, road dust, metal processing, industrial emissions but mostly, about $50 \%$, vehicular traffic.

$\mathrm{PM}_{2.5}$ levels fluctuate between 45 and $15 \mu \mathrm{g} / \mathrm{m}^{3}$ depending on the location of the measurement station and the time of the year. Average annual value is $24.3 \mu \mathrm{g} / \mathrm{m}^{3}$, barely 
below the maximum allowed in the national guideline [11]. PST in Bogotá always tops the maximum recommended level of $100 \mu \mathrm{g} / \mathrm{m}^{3}$. A worrying fact is that the most affected areas in Bogotá (Puente Aranda, Fontibón, Tunjuelito and Kennedy) are precisely those where lower-income citizens live, and they are the majority of the population [12]. Occasional restrictions on the circulation of private vehicles and heavy trucks when contamination levels reach alarming levels result in even higher $\mathrm{PM}_{2.5}$ and $\mathrm{PM}_{10}$ measurements because industries and small businesses resort to older, smaller vehicles and public transport circulation increases. Recent research has determined that despite unsubstantiated claims to the contrary by the Mayor of Bogotá, Enrique Peñalosa, particulate levels inside the buses of Transmilenio, the Bus Rapid Transit System are dangerously high, and they are even higher in some bus stations in the system [7].

Medellin has a smaller population than Bogotá but air pollution problems have become more serious because population density is higher, the valley area is smaller, the surrounding mountains are taller, industries operate throughout the city, not concentrated in some specific sections, and the concentration of cars and motorcycles per citizen is much higher. A vehicle census from 2014 reported 1,234,946 cars and motorcycles moving through Medellin. The Sistema de Alerta Temprana de Medellín y el Aburrá (SIATA) has 20 high-precision sensors monitoring air quality in Medellin [13]. $58 \%$ of $\mathrm{PM}_{2.5}$ particles in Medellín come from old trucks built in the 1990s or earlier and used to transport merchandise through the city. Most of them are owned by small entrepreneurs with no other sources of income so the authorities have faced stiff opposition to prohibit them and force their replacement.

Annual average $\mathrm{PM}_{10}$ was $61 \mu \mathrm{g} / \mathrm{m}^{3}$ with the most polluted months being April $\left(83 \mu \mathrm{g} / \mathrm{m}^{3}\right)$ and May $\left(72 \mu \mathrm{g} / \mathrm{m}^{3}\right)$, while for the remaining months, average emissions exceeded $60 \mu \mathrm{g} / \mathrm{m}^{3}$ (except October with $49 \mu \mathrm{g} / \mathrm{m}^{3}$ ). Annual $\mathrm{PM}_{2.5}$ average is $26.9 \mu \mathrm{g} / \mathrm{m}^{3}$ above the national guideline. $64.6 \%$ of this particulate material is related to vehicles while $8.5 \%$ is associated with industrial processes. Ozone annual average is $31 \mu \mathrm{g} / \mathrm{m}^{3}$ [14].

$\mathrm{PM}_{2.5}$ and $\mathrm{PM}_{10}$ emissions are substantial in Downtown Medellín, where there is a vast number of people. It has been estimated that around 1 million people intermittently walk in this area every day. Unofficial data suggests that around 9,000 informal street vendors work in Downtown Medellín and therefore are exposed to substantial air pollution [15]. But as recently as March 2019, 15 of the 20 monitoring stations in the city reported air pollution values above the maximum permitted. Bicycle circulation restrictions had to be applied as pollution levels were considered too unsafe.

Medical health expenses associated with environmental issues as calculated by the Colombian Department of Planning in 2015 top 2.6\% of the national GDP and result in more than 10,000 annual deaths. Between 2011 and 2014 there were 2,877,892 patients treated in Bogotá's hospitals due to illnesses related to poor air quality [16].

\section{THE DISTRUST OF THE AUTHORITIES AND THE EMERGENCE OF CITIZEN SENSING}

British journalist George Monbiot [17] argues that had governments, corporations and ordinary citizens put as much effort into preventing environmental catastrophe as they have spent on making excuses for inaction, they would have solved it by now. Powerful economic and political interests have blocked radical action and ridiculed civil society demands and initiatives around the world. The media, with a few exceptions, is disinterested or even actively hostile. When broadcasters cover these issues, they carefully avoid any mention of power, talking about air pollution as if it were a random occurrence driven by mysterious, passive forces. They mostly retransmit official communications that propose microscopic, temporary fixes for vast structural problems. In Colombia, and other Global South locations, 
the myth of development has been reworded [18] and used to delegitimize proposals to solve the air pollution problem and confront the crisis of the Anthropocene. Those who govern nations, manage corporations and shape public discourse cannot be trusted with the preservation of life on Earth. As Monbiot writes, there is no benign authority preserving us from harm. No one is coming to save us.

Additionally, when they exist, institutional monitoring systems around the world have drawbacks [19]: the instruments are large in size, weight and cost and are difficult to calibrate. Their placement in urban areas is impacted by human activities (e.g., construction).

But citizens and social movements are stepping up to the front. Researchers are talking about rising global do-it-yourself (DIY) activism and tactical media use [20]-[23]. Activists are not only raising public awareness of environmental problems but are increasingly taking a hands-on approach, researching the issues, discovering voids in authorities discourses and actions, designing and building tools to collect data, circulating information through social media, pressuring traditional media to focus on topics that matter and constantly scrutinizing institutions, officials and corporations.

Citizens and social movements are buying or building low-cost air pollution sensors to monitor their living environment by themselves, and they are doing it in supposedly democratic societies like the Netherlands, totalitarian regimes like China and poor countries like Colombia. These collectives are implementing community-driven sensing infrastructures in many cities around the world. They calibrate their sensors with data from the official monitoring stations and use them in under-monitored areas or even build mobile devices that they take on the road to gather data about their usual transportation routes. They use open hardware and software, upload data to open servers, add georeferenced information and try to spread their measurements and findings to relevant social actors and the general public. These Citizen Science practices are challenging, they do need professional knowledge and support to be able to retrieve reliable data, but as our research is starting to show, maker movements are starting to spread and are impacting traditional media and public sector agendas in Colombia. Sometimes they seem invisible in our daunting, saturated mediascape of today but they are learning to process big data, to create metadata and to use it in more accessible, everyday narratives that common people can relate to.

\section{CITIZEN SENSING IN BOGOTA AND MEDELLIN}

In this paper we focus on the work of two citizen collectives, CanAirIO (Canard in Spanish) in Bogotá, and UNLOQUER in Medellín.

\subsection{App CanAirIO}

The CanAirIO App is a citizen science initiative for the monitoring of air quality in Bogotá using PM 2.5 particulate material sensors. The sensors are low cost (Fig. 1) and are built by citizens in open workshops. There, the problem of air pollution is explained and the sensors are assembled collaboratively.

Daniel Bernal is an electronics engineer. Three years ago he started to ask himself "How could we trust an air monitoring network that is insufficient with only 13 stations in a city as big as Bogotá? In addition, the web page that shows the data is often out of work and the data it shows is incoherent". He came across an article on the Internet that argued that "if you do not feel satisfied about how the government measures air quality, do it yourself". It was an initiative taking place in Germany. The article explained how to assemble an air quality sensor. He brought some sensors from China and started working on building a reliable 
device to measure air quality. His early measurements detected that air pollution was especially troubling inside the Transmilenio bus stations.

Antonio Vanegas is another member of the CanAirIO App collective. He is a software engineer and develops applications for Windows. He became interested in the topic of air pollution during a trip to the Mediterranean island of Malta. The capital of the island does not have a metro system so public transport relies on a Bus Rapid Transit System similar to Bogotá's Transmilenio. But in Malta, bus emissions were not perceptible. There was no significant air pollution. Antonio Vanegas also spent some time in Berlin and followed the debates on the criteria to choose new public transport buses. He understood that the proposals included buses with much cleaner technologies than those chosen by the government of Bogotá. After returning to Colombia he researched the RMCAB air quality public monitoring network and considered it insufficient. He also noticed the data outages. He saw a TV interview of Daniel Bernal and contacted him. Antonio Vanegas and Daniel Bernal started working together in late 2016 and with time more people started to join them.

The members of the CanAirIO App citizen collective believe that the air pollution information provided by the RMCAB is not fully reliable. Daniel Bernal argues that the RMCAB sensors are installed at a height of between 6 and $10 \mathrm{~m}$, so therefore "the devices do measure in the lower atmosphere but not normal breathing height". The collective decided to create their own low-cost, portable sensors, "but with a comparable measurement efficiency as those of the high-cost sensors". Early prototypes were modified after some tests. They managed to contrast their low-cost sensor measurements with those of a high-cost sensor from the lab of one of the universities in Bogotá. They ended up developing a much better sensor, one with a deviation of only $3.4 \%$. The components of the sensor cost about $\$ 120,000$ pesos (US\$37). The core of the device is a Honeywell particulate material sensor that activates when it receives air from a small fan. The device can be connected to a mobile phone via Bluetooth and through the CanAirIO App air pollution data is uploaded to the internet creating a collaborative georeferenced map of air quality in Bogotá (Fig. 2). The app is available on Google Play.

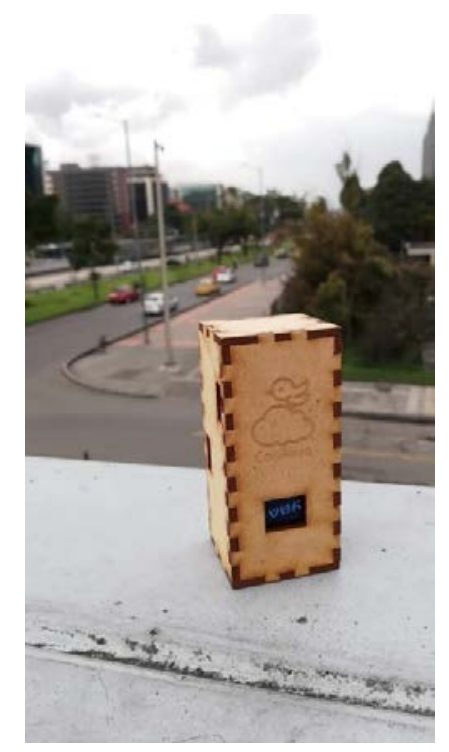

Figure 1: The CanAirIO sensor [24]. (Source: Medium $@$ C.) 
The CanAirIO App collective wants more citizens to build and use their sensors. So far in 2019 they have conducted two open workshops that help participants build their own sensors from scratch. The workshops last two hours (Fig. 3).

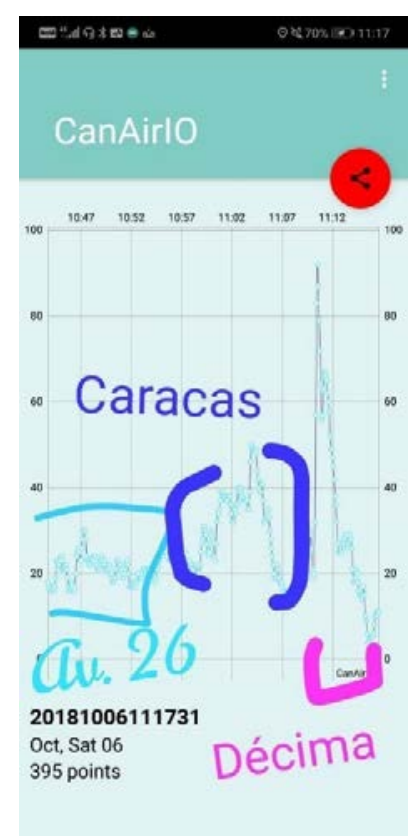

Figure 2: Air pollution data visualization on the CanAirIO app [25]. (Source: Medium (C.)

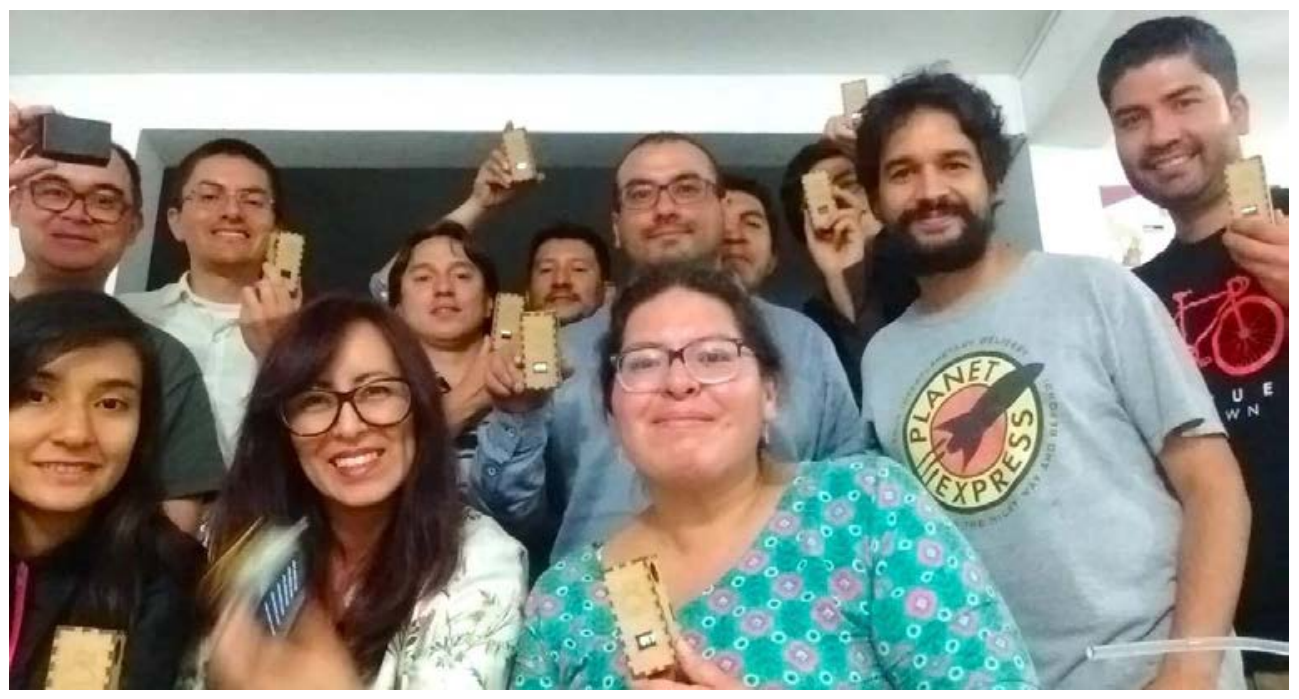

Figure 3: Common citizens of Bogotá showing their newly built CanAirIO sensors [25]. (Source: Angelica Zambrano@).) 
Currently there are more than thirty of these citizen sensors in Bogotá. The goal is to have between 100 and 200 citizens with sensors reporting to form a real and collaborative map of air quality in Bogotá. Although the application is a great initiative that has managed to sensitize many citizens to the serious condition of air pollution in Bogotá, there is still much to be improved in terms of data visualization. The air pollution map could be redesigned to make it easier to understand and follow by citizens with no prior knowledge of the problem. Up to now, the map can only be viewed by those who have the app installed on their smartphones. The collective consists of technology experts with little knowledge of community management and social communication.

\subsection{Unloquer}

They are a team of technology enthusiasts comprising professionals and amateurs that have been developing citizen science initiatives in Medellín since 2009. They have a hackerspace near downtown Medellín and sometimes convene citizens to explain their projects.

"About two years ago, with the interest of analyzing data, we wanted to see the condition of air quality in the city, but when we went looking for information, we did not find much available. So we decided to collect it ourselves" says Julián Giraldo, an electronics engineer. The problem became more acute with the passing of time. The local government has had to declare public emergencies prohibiting vehicle circulation in Medellín for days, at least 5 times in the past two years. Temporary tighter industrial emission regulations have been proposed but they have been criticized by corporations in the city. So Unloquer started developing a low-cost mobile sensor, to monitor air quality in Medellín.

The current team is made up of 15 members. They researched citizen sensing initiatives around the world and after testing different prototypes came up with a satisfactory, portable, very small $\mathrm{PM}_{2.5}$ sensor (Fig. 4). The sensors take into account humidity and temperature conditions. They can be taken on walking tours, on a bicycle, a motorcycle, a car or in any other vehicle.

The devices transmit data through WI-FI connections. They use a GPS to trace routes and add a timestamp to the measurements. Ten devices of this first version were manufactured. Today there are at least 30 Unloquer designed sensors installed in Medellín. The total cost of manufacturing the sensor is $\$ 300,000$ Colombian pesos (\$95 USD). Both the hardware and software designed are open source and documentation is available in the collective web site.

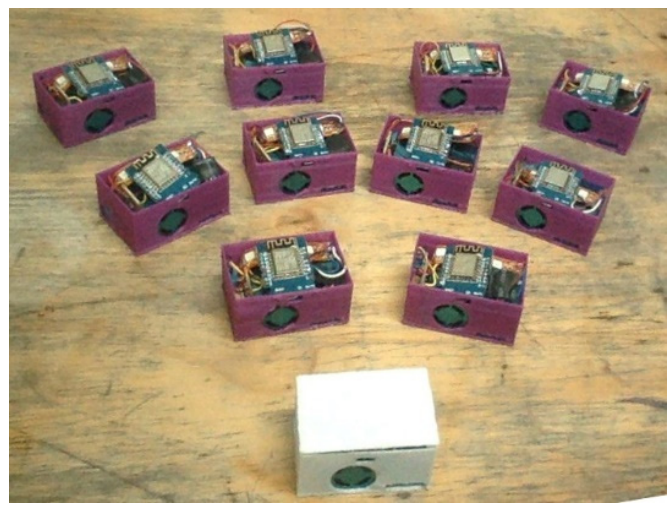

Figure 4: Unloquer air pollution sensors [26]. (Source: Unloquer@.) 
The project has not only developed a citizen network of mobile sensors to monitor Medellín's air quality, but also created a server system to store and facilitate the visualization of the data, which is readily available to citizens in the city (Fig. 5).

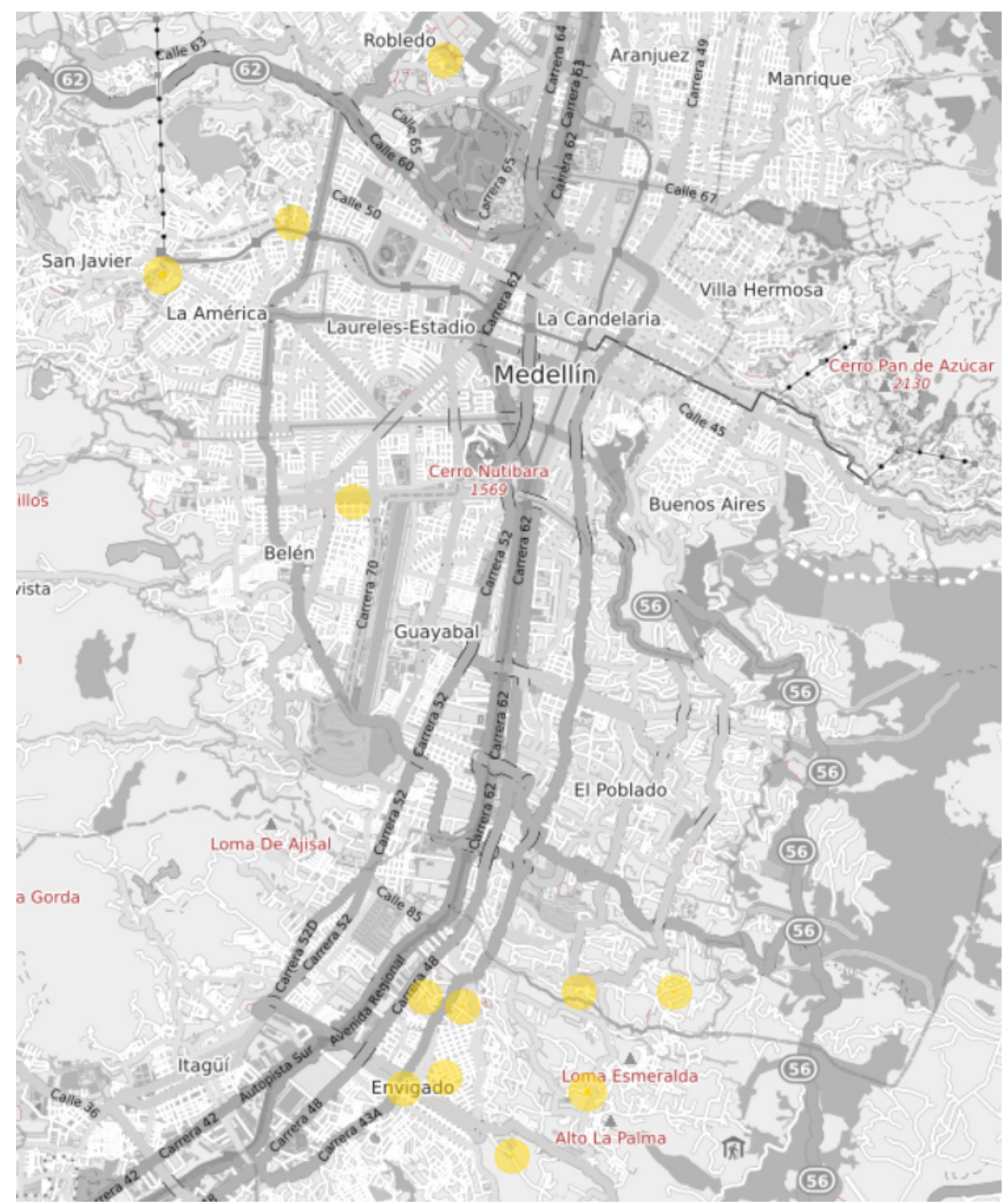

Figure 5: Air pollution map of Medellín obtained from citizen sensors [27]. (Source: Unloquer@.) 


\section{FINAL REMARKS}

There are critics of participatory sensing, both in the academic and in the public sectors. Distrust of the accuracy of the early Arduino devices, fears that citizen data could be manipulated by political and economic interests, the absence of audit mechanisms are common complaints. On the other hand, citizen sensing rises new challenges [28], such as protecting user private data and motivating and sustaining participation. Daniel Bernal considers that "the role of the authorities cannot be replaced. Participatory sensing data cannot be fully compared with government data, but they can be correlated and used to discover trends". Citizen sensing alone is not enough but could be a useful tool for activists to pressure governments and corporations to respond to social demands and finally take decisive actions to curb air pollution.

Pressure from Bogotá's citizen collectives using data obtained through participatory sensing and amplified by concerned sectors of traditional media resulted in the local government reconsidering its initial decision of renewing the Transmilenio fleet using only Diesel buses. Now, the local government will replace a total of 1,133 buses and they will rely on Diesel Euro V technology (59\%) and Natural Gas (41\%). The Mesa Técnica para la Calidad del Aire de Bogotá (MECAB), an umbrella organization that includes citizen collectives, academics and NGO's has managed to become a valid source for traditional media when reporting air pollution issues. The city government has had to interact with this organization as well.

Citizen collectives in Medellin, some of them using data from participatory sensing managed to force the local government to replace fifty buses from the public transport fleet with electric vehicles.

Definitive actions are still to be taken to solve the serious condition of air in Bogotá and Medellin, but citizen sensing collectives are managing to impact public institutions, corporate and general public agendas.

\section{REFERENCES}

[1] Ebenstein, A., Fan, M., Greenstone, M., He, G. \& Zhou, M., New evidence on the impact of sustained exposure to air pollution on life expectancy from China's Huai River Policy. PNAS, 114(39), pp. 10384-10389, 2017.

[2] Haraway, D., Anthropocene, Capitalocene, Plantationocene, Chthulucene: Making Kin. Environmental Humanities, 6, pp. 159-165, 2015.

[3] De Sousa-Santos, B., Renovar la teoría crítica y reinventar la emancipación social, CLACSO: Buenos Aires, pp. 15, 2006.

[4] Greenstone, M. \& Scharza, P., Is China Winning its War on Pollution?; Air Quality Life Index Update March 2018. https://epic.uchicago.edu/sites/default/files/UCHEPIC-AQLI_Update_8pager_v04_Singles_Hi\%20\%282\%29.pdf. Accessed on: 26 Apr. 2019.

[5] Meadows, D., (ed), The Limits to Growth; A Report for the Club of Rome's Project on the Predicament of Mankind, Universe Books: New York, 1972.

[6] Alcadia Mayor de Bogotá, Plan Decenal de Descontaminación del Aire para Bogotá, Alcadia Mayor de Bogotá: Bogotá, pp. 43-46, 2010.

[7] Morales-Betancourt, R., Galvis, B., Rincón-Riveros, J., Rincón-Caro, M., RodriguezValencia, A. \& Sarmiento, O., Personal exposure to air pollutants in a Bus Rapid Transit System: Impact of fleet age and emission standard. Atmospheric Environment, 202, pp. 117-127, 2019.

[8] Alcadia Mayor de Bogotá., Plan Decenal de Descontaminación del Aire para Bogotá, Alcadia Mayor de Bogotá: Bogotá, pp. 61-68, 2010. 
[9] Ramírez, O., Sánchez, A., Amato, F., Catacolí, R., Rojas, N. \& De la Rosa, J., Chemical composition and source apportionment of $\mathrm{PM}_{10}$ at an urban background site in a high-altitude Latin American megacity (Bogotá, Colombia). Environmental Pollution, 233, pp. 142-155, 2018.

[10] Alcadia Mayor de Bogotá, Plan Decenal de Descontaminación del Aire para Bogotá, Alcadia Mayor de Bogotá: Bogotá, pp. 69, 2010.

[11] Alcadia Mayor de Bogotá, Plan Decenal de Descontaminación del Aire para Bogotá, Alcadia Mayor de Bogotá: Bogotá, pp. 72, 2010.

[12] García, D., Calidad del aire y políticas públicas en Bogotá: una historia de injusticia ambiental. Ideas Verdes. Análisis Político, 14, pp. 1-22, 2018.

[13] Gaviria, C., Benavides, P. \& Tangarife, C., Contaminación por material particulado $\left(\mathrm{PM}_{2.5}\right.$ y $\left.\mathrm{PM}_{10}\right)$ y consultas por enfermedades respiratorias en Medellín (2008-2009). Revista de la Facultad Nacional de Salud Pública, 29(3), pp. 241-250, 2011.

[14] Posada, E., Gómez, M. \& Almanza, J., Análisis comparativo y modelación de las situaciones de calidad del aire en una muestra de ciudades del mundo. Comparación con el caso de Medellín. Revista Politécnica, 13(25), pp. 9-29, 2017.

[15] Gaviria, C. \& Martínez, D., Air Pollution and the Willingness to Pay of Exposed Individuals in Downtown Medellín, Colombia. Lecturas de Economía, 80, pp. 153182, 2014.

[16] Rodríguez-Villamizar, L., Rojas-Roa, N., Blanco-Becerra, L., Herrera-Galindo, V. \& Fernández-Niño, J., Short-Term Effects of Air Pollution on Respiratory and Circulatory Morbidity in Colombia 2011-2014: A Multi-City, Time-Series Analysis. International Journal of Environmental Research and Public Health, 15(8), 2018.

[17] Monbiot, G. Only rebellion will prevent an ecological apocalypse. The Guardian. 15 April 2019. www.theguardian.com/commentisfree/2019/apr/15/rebellion-preventecological-apocalypse-civil-disobedience. Accessed on: 26 Apr. 2019.

[18] Esteva, G., Development. The Development Dictionary. A Guide to Knowledge as Power, ed, J. Sachs, Zed Books: London and New York, pp. 1-23, 2010.

[19] Yi, W., Lo, K., Mak, T., Leung, K., Leung, Y. \& Meng, M., A Survey of Wireless Sensor Network Based Air Pollution Monitoring Systems. Sensors, 15(12), pp. 3139231427, 2015.

[20] Jiang, Q. et al., Citizen Sensing for Improved Urban Environmental Monitoring. Journal of Sensors, pp.1-9, 2016.

[21] Matsuzawa, S., Citizen Environmental Activism in China: Legitimacy, Alliances, and Rights-based Discourses. ASIANetwork Exchange, 19(2), pp. 81-91, 2012.

[22] Hasenfratz, D., Saukh, O., Sturzenegger, S. \& Thiele, L., Participatory Air Pollution Monitoring Using Smartphones. 2nd International Workshop on Mobile Sensing, pp. $1-5,2012$.

[23] Hua Xi, J., Communicating the Right to Know: Social Media in the Do-It-Yourself Air Quality Testing Campaign in Chinese Cities. International Journal of Communication, 8, pp. 1374-1393, 2014.

[24] canair.io., Citizen network for air quality monitoring. http://canair.io. Accessed on: 2 May 2019.

[25] Pàez, J. D. R., En 6 horas charladitas se puede reportar la calidad del aire en Bogotá. Medium, 2018. https://medium.com/@jdreyespaez/en-6-horas-charladitas-se-puedereportar-calidad-de-aire-en-bogot $\% \mathrm{C} 3 \% \mathrm{~A} 1-88 \mathrm{ca} 8 \mathrm{~d} 5 \mathrm{bb} 617$. Accessed on: 2 May 2019.

[26] Hackerspace Medellin, Air quality agents. http://wiki.unloquer.org/personas/ brolin/proyectos/agentes_calidad_aire. Accessed on: 2 May 2019. 
[27] https://bit.ly/2vkDBUi. Accessed on: 2 May 2019.

[28] Mendez, D., Colorado, J., Rodriguez, L., Chacon, A., \& Hernandez, M., Monitoring Air Pollution by Combining a Static Structure with a Participatory Sensing Approach: Design and Performance Evaluation. International Journal of Sustainable Development, 13(4): 638-652, 2018. 